\title{
Children's Ability to Recall Obligatory and Optional Acts within a Script and Over Time
}

\author{
Emily Laccona ${ }^{1}$, Betty Kollia ${ }^{1} \&$ Jim Tsiamtsiouris ${ }^{1, *}$ \\ ${ }^{1}$ William Paterson University, 300 Pompton Road, Wayne, NJ 07470 USA \\ *Correspondence: William Paterson University, 300 Pompton Road, Wayne, NJ 07470 USA. \\ E-mail: tsiamtsiourisj@wpunj.edu
}

Received: September 15, 2017 Accepted: October 31, 2017 Published: November 15, 2017

doi:10.5296/ije.v9i4.11873 URL: https://doi.org/10.5296/ije.v9i4.11873

\begin{abstract}
The goal of this research was to investigate children's recall of optional and obligatory elements of a script-based story as the retention period increased. Typically developing children, 20 kindergarteners and 20 second graders, participated. Children were asked to retell a story immediately after exposure to it, as well as one week post-, and two weeks post-exposure. Findings provide evidence that children of both age groups were able to marshal their script knowledge to recall stories over time. Older children were able to recall more elements and more of both, obligatory and optional elements, than younger children across all recall attempts.
\end{abstract}

Keywords: children, scripts, recall, obligatory elements 


\section{Introduction}

\subsection{Memory and Story Recall}

The development of memory plays a crucial role in overall language development. Psychologists as well as educators need to have a general understanding of the capacity of children of different ages to learn and remember information in order to assist in their overall memory and language development (Gatherole, Pickering, Ambridge, \& Wearing, 1998; Montgomery, Magimairaj, \& Finney, 2010; Newbury, Klee, Stokes, \& Moran, 2016). As children age, they become more proficient in their ability to use strategies for encoding, storing, and retrieving information (Coffman, Ornstein, McCall, \& Curran, 2008). By understanding their capacities at different ages, educators and specialists will be able to create educational experiences that maximize all students' abilities to learn. Additionally, understanding how all children learn and remember information is beneficial when creating activities for children with poor memory function such as those with auditory processing disorders and language impairments (Montgomery, Magimairaj, \& Finney, 2010).

The most influential account of a working memory model involves a central executive system that is responsible for a range of regulatory functions including attention, the control of action, and problem solving (Gatherole, Pickering, Ambridge, \& Wearing, 1998). Attentional control contributes to a person's capacity to devote mental energy to different levels of a task and sustain attention to a task while blocking irrelevant information and stimuli. This allows them to control the action and solve the problem on hand. These capacities increase from early childhood into adolescence. Many studies have focused on how children and adults store and organize information by assessing their ability to recall stories (Slackman \& Nelson, 1984; Hudson \&Nelson, 1983; McCartney \&Nelson, 1981; Mandler \& DeForest, 1979; Stein \& Glenn, 1979; Schank \& Abelson, 1977). A person's ability to produce a high-quality narrative of a previously experienced event may indicate that their underlying memory representation of the event is well-structured, elaborate, and inter-connected (Kulkofsky \& Klemfuss, 2008). Individuals embed the information they are trying to remember into a schema. A schema is defined as a mental representation of a spatially and temporally organized set of expectations about how things will take place (Slackman \& Nelson, 1984; Hudson \& Nelson, 1983; McCartney \& Nelson, 1981; Mandler \& DeForest, 1979; Stein \& Glenn, 1979). Different types of schematically organized knowledge include events, scenes, and stories. Schematic structures are automatically activated during familiar situations to help guide one's comprehension of the event or story and are later reactivated during one's recall attempt (Slackman \& Nelson, 1984).

\subsection{Development of Script}

Researchers have proposed that young children's knowledge is organized around schematic structures (Slackman \&Nelson, 1984; Hudson \& Nelson, 1983; McCartney \& Nelson, 1981; Mandler \& DeForest, 1979; Stein \& Glenn, 1979; Hayward, Gillam, \& Lien, 2007; Nelson, 1986; Nelson \& Gruendel, 1986). Children are constantly learning and forming cognitive representations of the experiences they encounter. Whether they are direct experiences, such as going to school or going to a restaurant, or indirect experiences through the reading of 
books about particular events, children are exposed to various events often enough that they eventually become routine for them (Schank \& Abelson, 1977). These mental routines are better known as scripts. As originally defined by Schank and Abelson (1977) a script is a schema for a familiar event that consists of a spatially and temporally organized framework. All the actions within a script have a temporal and causal connection and are centered around a specific goal (Nelson, 1986; Schank \& Abelson, 1977). Within a script these actions are also considered either obligatory or optional. For example, in a bedtime script, the goal is going to bed; brushing your teeth is obligatory while reading a story is optional. McCartney and Nelson (1981, p.59) summarized in their article that a script "contains certain basic or obligatory events in sequence and predicts open slots for optional objects and events and what they may contain, and appropriate roles in the action and who can fill them." As a result, when a child is asked to recount a script-based event to which they have been exposed repeatedly, they are able to recall the framework of the specific event in its sequential order, as well as fill the gaps with optional and context-appropriate details. Script frameworks are not specific to a single experience. Therefore, the skeletal structure of a script should be able to be applied to all episodes of a particular event. According to Nelson (1986), the skeletal structure of a script plays a significant role in one's memory development as well as how he/she learns to organize world knowledge.

Additionally, experiences are what shape the creation of scripts. Therefore, adults play a crucial role in helping children organize their world knowledge. Repeated exposure to indirect and direct script-based experiences will allow children to gain a better understanding of what is supposed to happen in routine events. As children participate in scripted events, adults need to provide guidance and direction in order to ensure that the scripts are being learned (Nelson \& Gruendel, 1986).

\subsection{Research on Children's Use of Scripts to Recall Stories and Events}

According to Slackman and Nelson (1984) in order understand how a child's memory develops, it is necessary to know how the child organizes their knowledge as well as how their organization changes as a result of time and experience. Several studies have investigated children's use of scripts as a strategy to recall stories and events. Through the use of script-based story recalls researchers have been able to assess the script knowledge of both adults and children. A script-based story typically consists of a short story embedded within a familiar script. The script-based story maintains the structure of a script framework, while including natural aspects of a narrative as well. According to Hayward, Gillam, \& Lien (2007), retelling a script-based story is thought to be less cognitively demanding than recalling a fictional narrative. Additionally, researchers have found that script knowledge not only helps one recall stories and events, but also guides their comprehension. (Hudson \& Nelson, 1983; McCartney \& Nelson, 1981; Slackman \& Nelson, 1984; Mandler \& DeForest, 1979).

In an effort to determine at what age children develop script-based knowledge, Nelson and Gruendel (1986) conducted a study involving preschool children. While examining children's reports of familiar events Nelson and Gruendel (1986) found that children as young as 3 
years old are able to give accounts that follow a general form, are temporally correct, and consistent in content. McCartney and Nelson (1981) performed a study with 5 and 7 year olds on their ability to recall stories about familiar dinner and bedtime events. Their study involved telling the children two script-based stories and having them immediately recall the stories they were told. Hudson and Nelson (1983) performed a study on preschool and first graders to investigate their use of scripts in a story recall by manipulating the amount of goal information and the temporal sequence of stories about familiar events. Both studies found that children were able to recall the main events better than the details. For example, McCartney and Nelson (1981) found that children in both Kindergarten and second grade recalled more core events about a bedtime emphasis story than the filler events. Additionally, Hudson and Nelson (1983) found that children in first grade are able to temporally sequence the events and repair sequences that did not follow the canonical order of the script. The canonical order of the script is the logical sequence the particular routine takes place in. For example, in a restaurant script, the waitress brings the menus before you receive your food. Mandler and DeForest (1979) found that younger children were unable to recall stories in any order other than their canonical form. Therefore, it appears, that "younger children rely more on script structures to aid in their comprehensions and memory than older children and adults" (Hudson \& Nelson, 1983, p. 626).

While most research examined children's ability to recall stories immediately, few studies added an extra condition into their methodology, namely, time. Through an experiment that involved adults listening to a script-based story and recalling it a half hour later and one week later, Graessar, Woll, Kowalski, and Smith (1980) concluded that, as the retention period increased, adults were more likely to use general scripts of their everyday life to guide their retrieval. Graessar et al. (1980) found that using general schemata can assist in the search, examination, and evaluation of specific events trying to be recalled. They also found that as the retention period increased, participants recalled more typical actions than atypical actions within the story. This corresponds with the findings of McCartney and Nelson (1981) and Hudson and Nelson (1983) who found that children are more likely to include main elements of a story than details. Grasser et al. (1980) concluded that, as a result of using more generic scripts, the subjects' story recounts became more of a reconstruction rather than a reproduction of the original form. Based on the research of Grasser et al. (1980), Slackman and Nelson (1984) conducted a study that examined children's ability to use script knowledge to recall stories as the retention period increased. However, unlike Grasser et al. (1980), who used a retention period of one week, Slackman and Nelson (1984) had the children recall the stories after four days. Slackman and Nelson (1984) found that like the adults in Grasser's et al. (1980) study, children recalled very general elements of the scripted stories in the delayed recall. Therefore, Slackman and Nelson's (1984) study concluded that schematic organization guides children's representation of unfamiliar script like narratives. That is, when information is organized in a logical manner as it is within a script, children are able to relate to the story better and ultimately recall the story more accurately. Additionally, Slackman and Nelson (1984) found that the difference between younger and older children in their schematization over time is that younger children "display less evidence of constructive processing and are apparently more dependent on an invariant, schematic organization of input material to guide 
recall” (1984, p. 339).

\subsection{Clinical Implications}

Speech language pathologists, psychologists as well as educators need to have a general understanding of the capacities of children of different ages to learn and remember information in order to assist children in their overall development of memory (Gatherole, 1998; Montgomery, Magimairaj, \& Finney, 2010; Newbury, Klee, Stokes, \& Moran, 2016). The identification of effective methods of remediation is contingent upon a better understanding of different learning profiles and memory abilities in children (Gatherole, 1998). This understanding is crucial when working with children with language impairments and weaknesses in organizing information and patterns (Hayward, 2007; Montgomery, Magimairaj, \& Finney, 2010; Newbury, Klee, Stokes, \& Moran, 2016). Therefore, identifying children with these difficulties can be beneficial while planning intervention with speech language pathologists and educators alike. Coffman, Ornstein, McCall, \& Curran (2008) have shown that, as children get older, they become more capable of using strategies like script knowledge to help them encode, store, and retrieve information. Therefore, as these abilities improve it is important that the environments children are surrounded by enhance the growth of mnemonic strategies even further. According to Hudson and Nelson (1983), understanding how an individual organizes their knowledge plays a crucial role in determining how that individual will remember any information presented to them. If a child displays difficulty when retrieving information stored in their memory, it is likely that the child will have difficulty with all memory tasks. Therefore, research involving children's use of script knowledge to recall stories and events will provide insight regarding how children recall information and what information they will recall. Thus, these findings give substantial support for therapists as well as educators to identify how children organize stored information they are exposed and what information they will recall.

\subsection{Need for Current Research}

Many studies have researched how adults as well as children store and organize information they are exposed to by assessing their ability to recall stories (Slackman \& Nelson, 1984; Hudson \& Nelson, 1983; McCartney \&Nelson, 1981; Mandler \& DeForest, 1979, Stein \& Glenn, 1979; Schank \& Abelson, 1977). Previous studies have focused on understanding children's ability to use scripts as a method of recalling unfamiliar stories and events. These studies looked at the age in which this skill is developed, the elements of the story the children were most likely to recall, the temporal sequencing of the child's recalled acts, and the cohesiveness of the elements (Hudson \& Nelson, 1983; McCartney \& Nelson, 1981; Slackman \& Nelson 1984; Mandler \& DeForest, 1979). Additionally, previous studies have analyzed children's immediate recall (McCartney \& Nelson, 1981; Nelson \& Gruendel, 1986; Mandler \& DeForest, 1979), 24-hour recall (Hudson and Nelson, 1983), and one study examined recall after four days (Slackman \& Nelson, 1984). However, studies have not looked at what happens to a child's recall when the interval of retention is increased beyond four days.

As a result of the dearth of research in the area of children's ability to recall stories over an 
extended period of time (more than four days), the purpose of the current study is to identify what happens to children's recall of obligatory and optional elements, as well as the temporal sequences of acts as the retention period is increased to three weeks. The present study consisted of presenting to kindergarten and second graders a script-based story. After listening to the story, children were asked to recall what they just heard. Non-biased questions were used in order to assist in the children's recall. One week after being presented with the story the children were asked to recall the story once again. Finally, two weeks after the initial presentation of the story, the children will be asked to recall the story for the last time. All story recalls were transcribed and analyzed.

It is hypothesized that younger children would include fewer optional than obligatory elements and make more violations in the temporal order of events than older children. In addition, it is hypothesized that, as the retention period increases, both young and old children are more likely to generalize the story so that it will still contain its temporal order, however, their stories will contain overall fewer optional as well as fewer obligatory elements.

\section{Methods}

\subsection{Participants}

Twenty kindergarteners and 20 second graders, from a middle class suburban area, participated in the study. Approximately half of the children in each age group were males and half were females. The kindergarteners ranged in age from 5;3 (year; months) to 6;4 (mean age 5;9) and the second graders ranged in age from 7;3 to 8;6 (mean age 7;8). All forty of the children were from monolingual English speaking families and attended an elementary school in the Wayne Public School District in Wayne, NJ. The study was reviewed and approved by the Assistant Superintendent of the Wayne Public Schools and the Institutional Review Board of William Paterson University. Additionally, parents indicated consent for their child's participation.

\subsection{Materials}

One script-based story was used in the study. The story was about two children, a boy and girl, going to a diner with their mother. A picture that displayed two children sitting at a restaurant table with their mother was also used. The picture was used as a visual aid to remind children of the restaurant script. However, it did not depict any information that could influence the child's story recall.

\subsection{Procedure}

The story was presented to each child individually in a quiet setting. In order to activate prior knowledge of a restaurant script framework, the examiner asked the child before presenting the story, if he/she had ever eaten at a diner. The examiner then showed to the child a picture that displayed two children sitting at a restaurant table with their mother. The examiner then presented the pre-recorded story to each child using a portable audio player. Each child was 
then asked to tell the restaurant story back to the examiner. One week later the children were asked to retell the restaurant story for the second time. Two weeks after the initial presentation, the children were asked to retell the story for the third time. All responses provided by the children were recorded on a portable audio-recorder.

\subsection{Scoring}

For purposes of data collection the restaurant story presented to the children was segmented into 20 C-units (Appendix A). According to Loban (1976), a C-unit consists of an independent clause and its modifiers. Next, the children's stories were transcribed, segmented into C-units and compared to the C-units identified in the restaurant story for each of the three recall attempts. Children received credit for $\mathrm{C}$-units that were identical or semantically equivalent to the original. Children's stories were also analyzed for the inclusion of obligatory and optional acts. Of the story's 20 C-units, 10 were considered obligatory and 10 were considered optional (see Appendix A). According to Schanck and Abelson (1977) obligatory acts are the most important elements in the representation. Obligatory acts in a restaurant script were considered those that answer general script questions about going to a restaurant. These questions included "Where did they eat? What did they eat? Did they pay the bill?" and "Where did they go after they ate?" Those C-units that did not answer one of these questions were defined as optional. Temporal sequencing was also examined. The number of temporal sequence errors found within in the children's attempts were counted and recorded.

\section{Results}

Children's stories were transcribed and analyzed to examine the total number of acts, obligatory acts, and optional acts recalled for each grade for the three recall attempts. Sequential errors within the children's stories were also analyzed for each grade for the three recall attempts.

\subsection{Total Acts Recalled}

Table 1. Means and Standard Deviations for Total Number of Acts Recalled by Each Grade

\begin{tabular}{lcccccc}
\hline & \multicolumn{2}{c}{ Kindergarten $(N=20)$} & \multicolumn{2}{c}{ Second Grade $(N=20)$} & \multicolumn{2}{c}{ Total $(N=40)$} \\
\hline \multicolumn{1}{c}{ Attempt } & $\mathrm{M}$ & $\mathrm{SD}$ & $\mathrm{M}$ & $\mathrm{SD}$ & $\mathrm{M}$ & $\mathrm{SD}$ \\
\hline Immediate Recall & 8.89 & 2.94 & 12.90 & 2.25 & 10.88 & 3.30 \\
1 Week Recall & 7.60 & 3.17 & 10.60 & 2.35 & 9.10 & 3.14 \\
2 Week Recall & 7.30 & 2.98 & 10.60 & 1.85 & 8.95 & 2.96 \\
\hline
\end{tabular}

Table 1 shows the means and standard deviations for the two grades regarding the total number of acts recalled at each attempt. A 3 X 2 mixed ANOVA was performed on the total number of acts recalled, with grade (kindergarten and second) as the between-subjects factor, and the time of recall (immediate, one week, two weeks) as the within-subject factor. Data 
were evaluated to determine whether they met assumptions of parametric statistical analysis. The assumption of sphericity was met based on results from the Mauchley's Test $(p=.370)$.

There was a significant main effect of the time $\left[F(2,76)=15.26, p<.001, \eta^{2}=.30\right]$. Partial eta squared indicated a moderate effect. There was no significant interaction effect of time of recall and grade, $[F(2,76)=.97, n s]$. A significant main effect of grade was found, $[F(1,38)=$ 24.21, $\left.p<.001, \eta^{2}=.389\right]$, with second graders recalling more acts than kindergarteners. Figure 1 shows the total number of acts recalled by both kindergarteners and second graders.

As a whole, a significant decline in the total number of acts recalled for both kindergarteners and second graders was observed between immediate recall of the story $(\mathrm{M}=10.88, \mathrm{SD}=3.30)$ and recall after one week $(\mathrm{M}=9.10, \mathrm{SD}=3.14)(\mathrm{p}<0.001)$, as well as between immediate recall of the story and recall after two weeks $(\mathrm{M}=8.95, \mathrm{SD}=2.96)(\mathrm{p}<0.001)$. However, there was no significant decrease in the total number of acts recalled from one week post-exposure to two weeks post-exposure.

\subsection{Obligatory Acts}

Table 2. Means and Standard Deviations for Obligatory Acts Recalled by Each Grade

\begin{tabular}{lcccccc}
\hline \multicolumn{1}{c}{ Total $(N=40)$} & \multicolumn{3}{c}{ Kindergarten $(N=20)$} & \multicolumn{3}{c}{ Second Grade $(N=20)$} \\
\hline \multicolumn{1}{c}{ Attempt } & $M$ & $S D$ & $M$ & $S D$ & $M$ & $S D$ \\
\hline Immediate Recall & 5.85 & 1.81 & 7.60 & 0.94 & 6.73 & 1.68 \\
1 Week Recall & 4.95 & 2.21 & 7.15 & 1.31 & 6.05 & 2.11 \\
2 Week Recall & 5.00 & 1.86 & 7.40 & 0.94 & 6.20 & 1.90 \\
\hline
\end{tabular}

Table 2 shows the means and standard deviations for the two grades regarding the number of obligatory acts recalled at each attempt. A 3 X 2 mixed ANOVA was performed on the number of obligatory acts recalled, with grade (kindergarten and second) as the between-subjects factor, and the time of recall (immediate, one week, two weeks) as the within-subject factor. Data were evaluated to determine whether they met assumptions of parametric statistical analysis. The assumption of sphericity was met based on results from the Mauchley's Test $(p=.846)$.

There was a significant main effect of the time $\left[F(2,76)=3.79, p=.029, \eta^{2}=.089\right]$. Partial eta squared indicated a weak effect. There was no significant interaction effect of time of recall and grade, $[F(2,76)=.823, n s]$. A significant main effect of grade was found, $[F(1,38)$ $\left.=27.57, p<.001, \eta^{2}=.389\right]$, with second graders recalling more obligatory acts than kindergarteners.

Collectively kindergarteners and second graders showed a significant decline in the total number of obligatory acts recalled between immediate recall of the story $(M=6.72, S D=1.68)$ and recall after one week $(M=6.05, S D=2.11)(p=0.02)$, as well as between immediate recall of the story and recall after two weeks $(M=6.20, S D=1.90)(p=0.05)$. However, there was no significant decrease in the total number of obligatory acts recalled from one week 
post-exposure to two weeks post-exposure.

\subsection{Optional Acts}

Table 3. Means and Standard Deviations for Optional Acts Recalled by Each Grade.

\begin{tabular}{lcccccc}
\hline \multicolumn{2}{c}{ Kindergarten $(N=20)$} & \multicolumn{2}{c}{ Second Grade $(N=20)$} & \multicolumn{3}{c}{ Total $(N=40)$} \\
\hline \multicolumn{1}{c}{ Attempt } & $M$ & $S D$ & $M$ & $S D$ & $M$ & $S D$ \\
\hline Immediate Recall & 3.00 & 1.65 & 5.30 & 1.78 & 4.15 & 2.06 \\
1 Week Recall & 2.65 & 1.35 & 3.45 & 1.36 & 3.05 & 1.40 \\
2 Week Recall & 2.30 & 1.59 & 3.20 & 1.36 & 2.75 & 1.53 \\
\hline
\end{tabular}

Table 3 shows the means and standard deviations for the two grades regarding the number of optional acts recalled at each attempt. A 3 X 2 mixed ANOVA was performed on the number of optional acts recalled, with grade (kindergarten and second) as the between-subjects factor, and the time of recall (immediate, one week, two weeks) as the within-subject factor. Data were evaluated to determine whether they met assumptions of parametric statistical analysis. Assumption of sphericity was met based on results from the Mauchley's Test ( $p=.144)$.

There was a significant main effect of the time $\left[F(2,76)=16.66, p<0.001, \eta^{2}=.305\right]$. Partial eta squared indicated a moderate effect. There was a significant interaction effect of time of recall and grade, $[F(2,76)=5.39, p=0.006]$. A significant main effect of grade was found, $\left[F(1,38)=12.21, p=.001, \eta^{2}=.243\right]$, with second graders recalling more optional acts than kindergarteners. Figure 3 shows the number of optional acts recalled by both kindergarteners and second graders.

Collectively kindergarteners and second graders showed a significant decline in the total number of optional acts recalled between immediate recall of the story $(M=4.15, S D=2.06)$ and recall after one week $(M=3.05, S D=1.40)(p<0.001)$, as well as between immediate recall of the story and recall after two weeks $(M=2.75, S D=1.53)(p<0.001)$. However, there was no significant decrease in the total number of optional acts recalled from one week post-exposure to two weeks post-exposure.

To further explore the significant interaction effect between time of recall and grade, a Tukey's LSD comparison was used. A Bonferroni correction was applied and so all effects are reported at a 0.0083 level of significance. Kindergarteners displayed no significant changes regarding their recall of optional acts from immediate recall to one week, immediate recall to two weeks, or one week to two weeks. However, second graders displayed a significant decrease in the number of optional acts recalled from immediate recall $(M=5.30$, $S D=1.78)$ to one week $(M=3.45, S D=1.36)$, as well as from immediate recall to two weeks $(M=3.2, S D=1.36)$. However, second graders did not display a significant decrease in the total number of optional acts recalled from recall after one week to two weeks. 


\subsection{Sequential Order}

Table 4. Means and Standard Deviations for Sequential Errors Made by Each Grade.

\begin{tabular}{ccccccc}
\hline \multicolumn{1}{c}{ Total $(\mathrm{N}=40)$} & \multicolumn{3}{c}{ Kindergarten $(\mathrm{N}=20)$} & \multicolumn{3}{c}{ Second Grade $(\mathrm{N}=20)$} \\
\hline \multicolumn{1}{c}{ Attempt } & $M$ & $S D$ & $M$ & $S D$ & $M$ & $S D$ \\
\hline Immediate Recall & .70 & .98 & .40 & .50 & .55 & .78 \\
1 Week Recall & .55 & .83 & .40 & .59 & .46 & .72 \\
2 Week Recall & .35 & .49 & .60 & .82 & .46 & .69 \\
\hline
\end{tabular}

Table 4 shows the means and standard deviations for the two grades regarding the number of errors children made in the sequential order of the story at each attempt. A 3 X 2 mixed ANOVA was performed on the number of errors children made in the sequential order, with grade (kindergarten and second) as the between-subjects factor, and the time of recall (immediate, one week, two weeks) as the within-subject factor. Data were evaluated to determine whether they met assumptions of parametric statistical analysis. The assumption of sphericity was met based on results from Mauchley's Test $(p=.085)$.

There was no significant main effect of time $[F(2,76)=.202, n s]$. There was no significant interaction of time of recall and grade, $[F(2,76)=.121, n s]$. There was no significant main effect of grade, $[F(1,38)=.159, n s]$.

\section{Discussion}

This study examined what happens to children's recall of a story when the retention period is increased more than one week. Specifically, it aimed to examine children's inclusion of obligatory and optional acts as well as the temporal sequence that their stories followed. Overall findings from this study provide evidence that children in both kindergarten and second grade are able to use their knowledge of a restaurant script to recall stories over time.

As predicted, older children were able to recall more elements and more of both, obligatory and optional elements, than younger children across all recall attempts. These findings are consistent with previous studies, which found that older children are able to recall more elements than younger children (Hudson \& Nelson, 1983; Slackman \& Nelson, 1984; McCartney \& Nelson, 1981). Slackman and Nelson (1984) found that children in first and third grade were able to recall more than those in preschool when presented with unfamiliar script based stories about visiting a friend and going to a restaurant. Likewise, McCartney \& Nelson (1981) found that children in second grade were able to recall more filler events than kindergarteners when asked to recall a story. The trend of older children including more optional elements than younger children found within this study is also consistent with the findings of Hudson and Nelson (1983). They suggested that even though "younger children are able to use schematic structures to guide retrieval automatically, with age children may also be able to use these structures more deliberately and are not necessary limited to only one automatic retrieval mechanism" (Hudson \& Nelson, 1983, p. 634). Therefore, with age, children are able to branch away from the general script to include more details that assist in 
making the story unique.

We also found that children in kindergarten and second grade were able to follow the general sequential order of the story regardless of the immediacy of the recall attempt. It was predicted that younger children would make more errors than older ones. However, it was found that both second graders and kindergarteners generally made between one or two errors in the sequence of the events of the story. This was consistent with the previous findings of Slackman and Nelson (1984) who found that there were no significant age differences in the temporal sequencing seen in story recalls by children in preschool, first grade, and third grade. McCartney and Nelson (1981) also found that children were able to sequence properly while recalling script-based stories about bedtime and eating dinner. Slackman and Nelson (1984) have suggested that because there are no significant age differences regarding the sequential order of children's recall, "this indicates that there are similar organizational principles guiding recall of script-like material" (p.338). That is, children are aware that scripts follow a specific order and that the sequence needs to be followed in order to recall the story accurately.

As predicted, as the retention period increased, both younger and older children generalized the story so that it contained its sequential order, but it contained overall fewer optional as well as fewer obligatory elements. More specifically, results from this study revealed that there was a significant decrease in the number of obligatory and optional elements recalled from immediate recall to one week post- and immediate recall to two weeks post-exposure. However, there was no significant change from one week to two weeks. This suggests that the time span from recall attempt one week post- to two weeks post- was not long enough to result in any significant change in the number of elements recalled. These results are consistent with those of Slackman and Nelson (1984) who found that after having children recall a story four days after initially hearing it, the children were able to recall more general items than specific ones. They also found that like the children in our study, delaying the recall caused the children to confuse and delete the optional elements, but not the obligatory ones. These findings are also in accord with Graessar et al. (1980) who found that as the retention period increased, their adult participants recalled more typical actions than atypical actions within the story they had to remember. They concluded that, as the retention period increased, adults were more likely to use general scripts of their everyday life to guide their retrieval. Overall, the findings of this study are consistent with previous research that shows memory for specific details decreases over time although the general idea of the story remains.

\section{Conclusion}

In conclusion, the results of this study demonstrated that children are able to use their preexisting knowledge of a script to assist in the retrieval of a story at a later date. As the retention period increased, children were more likely to generalize the story to fit a preexisting script they were familiar with. The fact that older children were able to recall more elements, especially optional elements, suggests that older children are less dependent 
on using a schematic organization of input material to guide in their recall. Possibly, the generic script has been sufficiently internalized so that the older children have the ability to be more flexible and include details that stray from the generic script.

\section{References}

Coffman, J.L., Ornstein, P.A., McCall, L.E., \& Curran, P.J. (2008). Linking teachers' memory-relevant language and the development of children's memory skills. Developmental Psychology, 44, 1640-1654. https://doi.org/10.1037/a0013859

Gathercole, S., Pickering, S., Ambridge, B., \& Wearing, H. (2004). The Structure of Working Memory From 4 to 15 Years of Age. Developmental Psychology, 40, 177-190. https://doi.org/10.1037/0012-1649.40.2.177

Gathercole, S.E. (1998). The development of memory. Journal of Child Psychology and Psychiatry, 39, 3-27. https://doi.org/10.1017/s0021963097001753

Graesser, A. C., Woll, S. B., Kowalski, D. J., \& Smith, D. A. (1980). Memory for typical and atypical actions in scripted activities. Journal of Experimental Psychology: Human Learning and Memory, 6(5), 503-515. https://doi.org/10.1037//0278-7393.6.5.503

Hayward, D.V., Gillam, R.B., \& Lien, P. (2007). Retelling a script-based story: Do children with and without language impairments focus on script and story elements? American Journal of Speech-Language Pathology, 16, 235-245. https://doi.org/10.1044/1058-0360(2007/028)

Hudson, J., \& Nelson, K. (1983). Effects of script structure on children's story recall. Developmental Psychology, 19, 625-635. https://doi.org/10.1037/0012-1649.19.4.625

Kulkofsky, S., \& Klemfuss, J.Z. (2008). What the stories children tell can tell about their memory: Narrative skill and young children's suggestibility. Developmental Psychology, 44, 1442-1456. https://doi.org/10.1037/a0012849

Loban,W. (1976). Language development: Kindergarten through grade twelve. Urbana, IL: National Council of Teaching English.

Mandler, J.M., \& DeForest,M. (1979). Is there more than one way to recall a story? Child Development, 50, 886-880. https://doi.org/10.2307/1128960

McCartney, K.A., \& Nelson, K. (1981). Children's use of scripts in story recall. Discourse Processes, 4, 59-70. https://doi.org/10.1080/01638538109544506

Montgomery, J., Magimairaj, B., \& Finney, M. (2010). Working Memory and Specific Language Impairment: An Update on the Relation and Perspectives on Assessment and Treatment. American Journal of Speech-Language Pathology, 19, 78-94. https://doi.org/10.1044/1058-0360(2009/09-0028)

Nelson, K. (1986). Event knowledge and cognitive development. In K. Nelson (Ed.), Event knowledge: Structure and function in development (pp. 1-21). Hillsdale, N.J.: Erlbaum. 


\section{Macrothink}

Nelson, K., \& Gruendel, J. (1986). Children's scripts. In K. Nelson (Ed.), Event knowledge: Structure and function in development (pp. 22-46). Hillsdale, N.J.: Erlbaum.

Newbury, J., Klee, T., Stokes, S., \& Moran, C. (2016). Interrelationships Between Working Memory, Processing Speed, and Language Development in the Age Range 2-4 years. Journal of Speech, Language, and Hearing Research, 59, 1146-1158. https://doi.org/10.1044/2016_jslhr-1-15-0322

Schank, R.C., \& Abelson, R.R. (1977). Scripts, plans, goals and understanding: An inquiry into human knowledge structures. Hillsdale, N.J.: Erlbaum.

Slackman, E., \& Nelson, K. (1984). Acquisition of an unfamiliar script in story form by young children. Child Development, 55, 329-340. https://doi.org/10.2307/1129946

Stein, N., \& Glenn, C.G. (1979). An analysis of story comprehension in elementary school children: A test of a schema. In R. O. Freedle (Ed.), New directions in discourse processing. Hillsdale, NJ: Ablex. 
Appendix A

\begin{tabular}{|c|c|c|}
\hline \multicolumn{2}{|r|}{ Story Element } & Obligatory/Optional \\
\hline 1 & On Monday Brian and Ava came home from school. & Optional \\
\hline 2 & Their mom said to them,"Tonight we are going out to eat." & Obligatory \\
\hline 3 & "Where would you like to go?" & Obligatory \\
\hline 4 & Brian and Ava quickly replied, "the diner!" & Obligatory \\
\hline 5 & So they all jumped in the car. & Optional \\
\hline 6 & And their mom drove them to the diner they always went to. & Obligatory \\
\hline 7 & They walked into the diner. & Optional \\
\hline 8 & And sat down at a table. & Optional \\
\hline 9 & The waitress brought them all menus. & Optional \\
\hline 10 & Brian ordered a hamburger with fries. & Obligatory \\
\hline 11 & Ava couldn't decide what she wanted. & Optional \\
\hline 12 & Their mom ordered a salad. & Obligatory \\
\hline 13 & Then Ava decided to order a grilled cheese sandwich & Obligatory \\
\hline 14 & While waiting for their food they colored. & Optional \\
\hline 15 & And their mom asked them what they did in school. & Optional \\
\hline 16 & Once their food came they ate it all up. & Obligatory \\
\hline 17 & After they were finished the waitress came and cleared the table. & Optional \\
\hline 18 & Finally their mom paid the bill. & Obligatory \\
\hline 19 & Ava and Brian ran to the car. & Optional \\
\hline 20 & And their mom drove them home. & Obligatory \\
\hline
\end{tabular}

\section{Copyright Disclaimer}

Copyright for this article is retained by the author(s), with first publication rights granted to the journal.

This is an open-access article distributed under the terms and conditions of the Creative Commons Attribution license (http://creativecommons.org/licenses/by/3.0/). 